\title{
A ESCUTA ATIVA E A ALTERIDADE COMO PRESSUPOSTOS PARA A LIBERAÇÃO DO PERDÃO PELA MEDIAÇÃO
}

\section{ACTIVE LISTENING AND ALTERITY AS ASSUMPTION TO THE FORGIVENESS THROUGH MEDIATION}

\author{
Charlise Paula Colet Gimenez ${ }^{1}$ \\ Alini Bueno dos Santos Taborda ${ }^{2}$
}

Recebido em: 29/05/2017

Aprovado em: 31/07/2017

"Que o perdão seja sagrado

Que a fé seja infinita

Que o homem seja livre Que a justiça sobreviva. "

(Ivan Lins e Vitor Martins)

\section{RESUMO}

O presente trabalho tem por finalidade debater a importância da escuta ativa e da alteridade no procedimento da mediação, como método eficaz

\footnotetext{
1 Doutora em Direito e Mestre em Direito pela Universidade de Santa Cruz do Sul - UNISC. Especialista em Direito Penal e Processo Penal pela Universidade Regional do Noroeste do Estado do Rio Grande do Sul UNIJUÍ. Professora dos Cursos de Mestrado e Graduação em Direito da Universidade Regional Integrada do Alto Uruguai e Missões - URI, campus Santo Ângelo. Coordenadora do Curso de Graduação em Direito da URI. Líder do Grupo de Pesquisa "Conflito, Cidadania e Direitos Humanos", registrado no CNPQ. Advogada. Atua no estudo do Crime, Violência, Conflito e Formas de Tratamento de Conflitos - conciliação, mediação, arbitragem e justiça restaurativa. E-mail: charliseg@santoangelo.uri.br
}

${ }^{2}$ Doutoranada e Mestre em Direito pelo Programa de Pós-Graduação stricto sensu em Direito da Universidade Regional Integrada do Alto Uruguai e Missões - URI, campus Santo Ângelo. Docente do Curso de Graduaçao em Direito da mesma universidade, campus Santiago. Advogada. E-mail: alinitaborda@gmail.com 
de resolução de conflitos sociais e local de liberação de perdão. Para a realização do presente estudo, adota-se o método de abordagem hipotéticodedutivo. Como vertente principal de discussão, destaca-se a importância do saber escutar como forma de criar empatia e, acima de tudo, estabelecer um ambiente mais afetuoso e propicio ao encontro de soluções satisfatórias para os conflitos. Apresenta-se, ainda, a importância da alteridade, como um ato de efetivamente ver e sentir o outro para que assim ocorra a chamada liberação do perdão enquanto possibilidade de reconciliação, transformação das relações conflituosas e o despertar para uma sociedade mais terna e pacífica.

\title{
PALAVRAS-CHAVE
}

Escuta ativa, alteridade, mediação, perdão.

\begin{abstract}
The purpose of this study is to discuss the importance of active listening and alterity in the mediation process, as an effective method of solving social conflicts and a place to release forgiveness. In order to realize this study, it is adopted the hipothetical-deductive method of approach. As a main strand of discussion, we emphasize the importance of knowing how to listen, as a way to create empathy and, above all, to establish a more affectionate and propitious environment for finding satisfactory solutions to conflicts. The importance of otherness is also emphasized as an act of effectively seeing and feeling the other, so that the so-called liberation of forgiveness may occur, as a possibility of reconciliation, transformation of conflictual relations and awakening to a more peaceful and peaceful society.
\end{abstract}

\section{KEYWORDS}

Active listening, alterity, mediation, forgiveness. 


\section{CONSIDERAÇÕES INICIAIS}

No estudo ora apresentado, realiza-se uma reflexão sobre a necessidade de uma escuta ativa, ou seja, sensível, e da alteridade, enquanto pressupostos para uma mediação eficaz. Apresenta-se a mediação como uma ideia pacificadora e ao mesmo tempo uma técnica de intervenção nos conflitos, pautada no diálogo franco e no comprometimento das partes envolvidas e, por isso, capaz de restabelecer e fortalecer suas relações.

Pela pluralidade de percepções, sentimentos, crenças e interesses, as relações são conflituosas. Nesse sentido, o conflito não é solucionado, mas pode ser trabalhado para que os envolvidos consigam compreender o mal praticado e desenvolver empatia entre si; escutar e atender as necessidades da pessoa que sofreu o dano e daquela que o provocou; estimular o compromisso de assumir as consequências dos próprios atos e a responsabilidade através da reflexão pessoal dentro de um processo colaborativo. Portanto, o que se pode é resgatar laços e, principalmente, a compreensão de que todos são pessoas valiosas que contribuem para a sociedade.

Percebe-se que a sociedade como um todo está acostumada ao conflito e se baseia para resolver o mesmo por meio da imposição de decisões, e não de forma negociada, afastando-se da autonomia de buscar o diálogo para o entendimento do conflito entre as partes. Entretanto, por vezes o conflito visualizado é apenas o aparente e, em outros momentos, é o escape para questões mais profundas que foram vivenciadas.

Dessa forma, tem-se a certeza que a busca pela paz como prática da cultura no tratamento de conflitos somente ocorrerá se houver a comunicação entre os envolvidos, e daí surge a necessidade de uma escuta ativa, capaz de oportunizar a alteridade e a sensibilidade com as dores alheias, capaz de possibilitar o perdão, como forma de intervir, positivamente, na vida do outro, possibilitando, também, a satisfação das necessidades não apenas individuais, mas coletivas.

Assim, o estudo que ora se apresenta tem por finalidade debater a importância da escuta ativa e da alteridade no procedimento da mediação, como método eficaz de resolução de conflitos sociais e local de liberação de perdão. Para tanto, adota-se o método de abordagem hipotético-dedutivo. 


\section{O PODER DA ESCUTA ATIVA33: DIFERENÇA ENTRE OUVIR E ESCUTAR}

A Comunicação é o núcleo das atividades humanas, e o que faz com que esse processo se realize de forma efetiva é o ato de escutar ativamente. Nesse sentido, a escuta é uma prática de comunicação que almeja que os obstáculos que se estabeleceram entre as partes de um conflito se eliminem, ou no mínimo sejam minimizadas.

Segundo Maria Odete Fachada, "a escuta ativa implica que prestemos atenção não só ao conteúdo da mensagem de cada uma das partes, mas também aos sentimentos e emoções nelas implicadas, aos índices não verbais e ao contexto em que a mensagem é proferida" (1991, p. 323).

A escuta ativa ${ }^{4}$ é um processo por meio do qual se deixa a outra pessoa saber que você está prestando atenção, busca estimular as pessoas a ouvirem umas as outras, provocando a expressão das emoções. Oportuniza o entendimento e a amenização dos conflitos, pois considera de extrema relevância a linguagem corporal e falada. Aqui pode-se falar em reciprocidade, uma vez que existem pessoas que estão de fato comprometidas no processo de ouvir, existe atenção, o que leva os indivíduos a estarem conectados e comprometidos.

Dessa forma, trata-se de desenvolver uma habilidade para compreender melhor as pessoas. Demonstra-se que todos são cuidadosamente ouvidos, olhando-se sempre nos olhos, e respondendo-se aos questionamentos proferidos. Assim, a escuta ativa é formada por duas partes, o escutar e a atitude, e se efetiva por uma comunicação clara e cuidadosa com o outro, criando vínculos de proximidade e confiança.

Partindo desta ideia de escuta ativa, compreende-se que esse método se reveste de enorme importância na resolução de conflitos, pois é fundamental que neste processo as partes envolvidas demonstrem a sua opinião e o

\footnotetext{
${ }^{3}$ Importante mencionar que o termo foi utilizado inicialmente para a negociação cooperativa pela Escola de Harvard. Ver Fischer, Robert; Ury, William; Patton, Bruce. Como chegar ao sim. Rio de Janeiro: Imago, 1994.

${ }^{4}$ Para Spengler (2014, p. 71), "a escuta ativa é a técnica por meio da qual o ouvinte busca compreender e se comunicar acer- ca do sentido e o motivo de mensagens verbais e não verbais (postura corporal), percebendo assim falante o que percebeu da declaração, tornando assim mais evidentes para este seus próprios motivos e sentimentos. A escuta ativa permite obter informações concernentes a elementos essenciais no pro- cesso de resolução de disputa, tais como credibilidade e interesse em resolver a questão".
} 
desacordo, sendo também importante explorar os sentimentos, os valores e as atitudes de todos os envolvidos. O saber escutar desenvolve a empatia, facilitando a obtenção de um ambiente mais adequado ao encontro de soluções satisfatórias para os conflitos. Pois, o terceiro facilitador da comunicação procura a retomada desta em bases eficientes e produtivas; a partir do diálogo os envolvidos serão mutuamente elucidados sobre a controvérsia, seus anseios e suas perspectivas, passando a poder perceber pontos comuns favoráveis ao alcance do consenso (DEMARCHI, 2007, p.57).

Sabe-se que muitas vezes os conflitos se ocasionam exatamente pela falta de comunicação, ou falha nessa comunicação. Em geral, os seres humanos apresentam dificuldades em aceitar posições diversas, fato que piora quando se está a lidar com problemas e questões nas quais os indivíduos estão emocionalmente envolvidos. Uma escuta ativa possibilita a outra pessoa a compreender que ela é objeto de atenção, demonstrando ao interlocutor estar interessado em seus pensamentos e em suas opiniões, razão pela qual se afirma que aqui as pessoas estão comprometidas no processo de ouvir e trocar informações ${ }^{5}$.

Especialmente na mediação, a escuta ativa pode ser vista como uma ferramenta necessária para o desenvolvimento da comunicação e de um melhor relacionamento entre os diferentes indivíduos. Conforme ressalta Juan Carlos Vezzulla, um novo tipo de escuta deve ser implementado, qual seja, a escuta ativa:

[...] do discurso dos mediandos sem a interferência de outros pensamentos, nem a tentativa de complementar, julgar ou associá-los a outras referências que não sejam as dos próprios participantes da mediação. Uma escuta que não fica somente na formalidade da história escutada, nem na sua falsa tentativa de compreensão causal (causa e efeito), nem na sua referência a uma ordem legal, psicológica ou sociológica que possam dar conta do que se diz (2013, p. 78).

O mediador deve atuar com concentração e sensibilidade, agindo de modo a fomentar o diálogo, e conduzi-lo para que as próprias partes busquem uma

\footnotetext{
${ }^{5}$ A escuta ativa e a mediação. INFORME NMC- XLIII- 9 a 15 de abril, 2010. Ministério Público do Ceará Disponível em:<http://www.pgj.ce.gov.br/n _especiais/nucleomed/pdf/NMCInforme43.pdf>. Acesso em: 20 mai.2017
} 
resposta satisfatória para as suas contendas. Ademais, deve empenhar-se em restaurar o canal de comunicação entre os envolvidos, propiciar um ambiente adequado para que os indivíduos envolvidos num conflito possam dialogar, assumindo uma conduta cooperativa e pacífica, auxiliando a descobrir os caminhos que podem conduzi-los às respostas de seus problemas. Visa-se promover entre os protagonistas do conflito traduzido em um preceito penal (crime), iniciativas de solidariedade, de diálogo e, contextualmente, programas de reconciliação (VEZZULLA, 2001).

Assim, para conseguir que a autocomposição seja exercida, a escuta ativa é essencial para que seu objetivo real seja alcançado, por meio da atenção que mediandos, bem como mediadores, dão aos fatos que os levam a estar interligados com o entendimento do conflito. Por meio desta escuta atenta e sensível, os envolvidos no conflito desenvolvem maior pré-disposição em acentuar a comunicação entre si, reconhecendo com maior facilidade os pontos controversos, e, consequentemente, a chegarem ao consenso de forma satisfatória. Nessa ótica, manifesta-se Sales:

O caminho da pacificação remete, necessariamente, à valorização do ser humano, concedendo-lhe formas e oportunidades de dialogar e participar da transformação de sua vida e de sua comunidade, o que, por conseguinte, gera nas pessoas o sentimento de inclusão e responsabilidade social (2010, p.09).

Com a escuta ativa, o mediador estimula os mediandos a se ouvirem, proporcionando a expressão das emoções. A melhor forma de comunicação é aquela que reconhece a necessidade do outro de se expressar. Justamente por isso os conselhos devem ser substituídos por uma escuta ativa para fins de mostrar que o que o outro diz e sente está sendo entendido e é relevante. Proferir conselhos normalmente se apresenta como um meio de dominação, uma maneira de assistencialismo, pois quem aconselha se coloca em posição superior. O conselho bloqueia as necessidades de expressão, reconhecimento e emancipação do aconselhado. Por essa razão, escutar e "escutar ativamente" é a melhor maneira de contribuir aos mediandos (VASCONCELOS, 2008, p.65-66).

A grande importância que deve ser dada a uma escuta ativa envolve a capacidade e a vontade de escutar e compreender a mensagem completa. E a mediação visa preponderantemente facilitar a comunicação, verbal, não-verbal e simbólica. A comunicação é papel de extrema importância para o sucesso de uma 
resolução pacífica e adequada dos conflitos trazidos ao mediador, uma vez que esse possui o papel de conduzir as partes ao seu empoderamento ${ }^{6}$, direcionandoas ao reconhecimento dos interesses dos outros (COSTA, 2015, p. 41)

Para comunicar-se de forma eficaz, é primordial buscar compreender o que está além das palavras e das emoções. Entender os gestos e o conteúdo verbal das pessoas é parte de um procedimento necessário para uma sessão de mediação de sucesso. Dessa forma, a escuta sensível serve como um mecanismo para evitar o maior obstáculo ao entendimento nas relações sociais que é a falha na comunicação, favorecendo o estabelecimento de uma nova cultura de pacificação e de comunicação não violenta, e que proporciona autonomia e empoderamento para resolver conflitos nas relações sociais.

\section{ALTERIDADE: SENTIR O OUTRO}

No convívio social, não importa em que contexto, haverá amor, amizade, admiração, e também haverá dissabores e desentendimentos. Portanto, os vínculos interpessoais, por inúmeras vezes, fazem os seres humanos vivenciar situações de conflito. Nesses momentos, emoção e razão colidem. Os conflitos ${ }^{7}$ são inerentes à vida em sociedade, cabendo aos seus integrantes buscar de forma pacífica, e respeitando cada quais suas liberdades perante a coletividade. Nesse sentido, afirma Muller que:

a humanidade do homem não se cumpre fora do conflito, mas sim para lá do conflito. O conflito está na natureza dos homens, mas quando esta ainda não está transformada pela marca do humano. O conflito é o primeiro, mas não deve ter a última palavra. [...] o homem não deve estabelecer uma relação de hostilidade, onde cada um é inimigo do outro, mas deve querer estabelecer uma relação de hospitalidade, onde cada um é hóspede do outro (2006, p.19).

\footnotetext{
"A palavra "empoderamento" é descrita em dicionários da língua portuguesa como Aurélio e Houaiss. De acordo com eles, o termo conceitua o ato ou efeito de promover conscientização e tomada de poder de influência de uma pessoa ou grupo social, geralmente para realizar mudanças de ordem social, política, econômica e cultural no contexto que lhe afeta. A ideia é dar a alguém ou a um grupo o poder de decisão em vez de tutelá-lo.

7 "O conflito tem uma significação sociológica, não somente para as partes diante dele, mas para cada um diante de si mesmo. A experiência demonstra que um con ito transforma cada um dos envolvidos, não somente na sua relação com o outro, mas consigo mesmo, pois existem, ao mesmo tempo, consequências des guradoras e puri cadoras, enfra- quecedoras e fortalecedoras" (SIMMEL, 1983, p. 150).
} 
Percebe-se que as pessoas elaboram decisões quando estão conscientes dos sentimentos criados pelos conflitos. Essa é a razão pela qual se deve integrar os sentimentos com as decisões, sem deixar que as emoções prejudiquem a racionalização do problema. E, dessa assertiva se extrai que não são os sentimentos propriamente que atrapalham a feitura das decisões, mas a forma como esses sentimentos são ventilados e respondidos (FOLBERG, 1988).

A mediação, nesse sentido, opera como um processo em que cada uma delas tem oportunidade de expor os seus interesses e as suas necessidades. Como decorrência, é possível descobrir um caminho que atenda, tanto quanto possível, aos legítimos interesses e às necessidades de ambas.

Neste rumo, manifesta-se Spengler:

A mediação, como espaço de reencontro, utiliza a arte do compartir para tratar conflitos e oferecer uma proposta inovadora de pensar o lugar do Direito na cultura complexa, multifacetada e emergente do terceiro milênio. Essa proposta diferenciada de tratamento dos conflitos emerge como estratégia à jurisdição tradicional, propondo uma sistemática processual que faça novas e mais abordagens numa realidade temporal inovadora e mais democrática (2008, p.75).

Assim, importante ressaltar o processo da mediação como um ato transformador por meio do qual é possível olhar para si mesmo por meio do olhar do outro (WARAT, 2001). Trata-se de uma co-responsabilidade solidária, pois assume-se um compromisso com as necessidades singulares da outra pessoa, desenvolvendo-se um respeito imediato pela pessoa do outro, que é meu semelhante.

O outro é visto, muitas vezes, como ameaça, negação, que questiona e se confronta com o poderio do eu. Nesse sentido, não é fácil encontrar um ser humano, é fácil reencontrar o que já é conhecido e é fácil encontrá-lo no simbólico. Porém, encontrá-lo " face a face" é, na maioria das vezes, muito mais difícil.

A busca pelo outro enseja uma certa inquietação no indivíduo, pois a responsabilidade e a necessidade chocam-se com a novidade. As insatisfações e decepções estarão sempre presentes, mas no momento que se propõe a se colocar no lugar do outro, essa ação vem precedida da responsabilidade pelo outro, instaurando um agir ético como alteridade. A alteridade, portanto, pode ser entendida como uma abertura para se repensar as nossas relações. 
É necessário salientar a importância da sensibilidade, pois nesse processo de se colocar no lugar do outro, é uma preocupação não para comigo, mas para com o outro. Em Warat, observa-se que "duas sementes não podem se relacionar, elas estão fechadas. Duas flores podem se relacionar, elas estão abertas" (2004, p.125). É necessário relacionar-se a partir do "centro", do interior subjetivo e não a partir da "periferia" (WARAT, 2004, p. 110).

Nesse sentido, é possível afirmar que:

a mediação deve ser compreendida como ética da alteridade, a qual reivindica a recuperação do respeito e do reconhecimento da integridade e da totalidade de todos os espaços de privacidade do outro, ou seja, um respeito absoluto pelo espaço do outro, e uma ética que rechaça o mínimo de movimento invasor em relação ao outro (GIMENEZ; SPENGLER, 2016, p. 122).

Dessa forma, se faz necessária uma ética da alteridade, pois o ser humano tem a obrigação de olhar, de se importar e sentir o outro. Como alerta Costas Douzinas, "no cara a cara, sou total, imediata e irrevogavelmente responsável pelo Outro que me encara" (1999, p.355). E, ainda, "o seu ser está ligado no interior dos outros, em buscar aquilo que está escondido, a verdade real, para assim então surgir ou trazer a tona a transformação que resultará na solução dos problemas" (WARAT, 2004).

No tocante à mediação, como ressalta Vezzulla, somente há pessoas e todas elas merecedoras de respeito. Em mediação, adota-se o conceito de respeito como o de se atender a todos por igual nas diferenças. Ou seja, as próprias diferenças são as que levam os seres humanos a serem iguais (2013, p.79)

Nessa senda, importante frisar que se busca pela prática da mediação a interação entre as partes envolvidas, quando um volta para o outro, em um diálogo franco e terno. De tal modo, para se resgatar a alteridade, a fim de reconstruir os vínculos esmagados "é necessário apostar na cultura, na alteridade, no desejo. A resistência cultural. A cultura da paz, da mediação, da alteridade do amor". (WARAT, 2010, p.24)

\footnotetext{
8 "A periferia de cada um está muito longe do próprio devir da identidade. A periferia é o lugar onde cada um de nós termina. A última fronteira que nos aproxima do mundo. Uma região altamente enganosa, onde prolifera todo tipo contrabando e defraudações. "WARAT, Luis Alberto. A Ciência Jurídica e seus dois maridos. Santa Cruz do Sul : Faculdades Integradas de Santa Cruz do Sul, 1985, p. 110
} 
Trazer o Outro para perto é embarcar para uma viagem infinita rumo ao desconhecido, "a alteridade é a possibilidade de conhecer a existência do outro. Eu existo na medida em que tenho a capacidade para reconhecer a existência do outro, e ele comporá a minha própria existência" (WARAT, 2010).

A mediação tem por objetivo responsabilizar os conflitantes pelo tratamento do seu litígio, unindo-os a partir de uma ética da alteridade; encontrar, com a atuação de um mediador, a garantia do sucesso, aparando as arestas e divergências, compreendendo as emoções reprimidas e alcançando um consenso que atenda aos interesses de cada envolvido e conduza à paz social (GIMENEZ; SPENGLER, 2016, p. 123).

Importante ressaltar que a possibilidade de olhar o conflito pelo olhar do outro faz com que o sujeito se depare e se submeta a um exercício de castração muitas vezes, pois, pode revelar questões perturbadoras. Entretanto, colocarse no lugar do outro, permitir-se senti-lo, mais que valorizar a outra pessoa, em um ato de ternura e possibilita transformar as relações conflitivas.

\section{A MEDIAÇÃO COMO UM INSTRUMENTO DE LIBERAÇÃO DO PERDÃO}

A intolerância, a ausência de parâmetros que orientem a convivência pacífica e a falta de habilidade para resolver os conflitos são algumas das principais dificuldades detectadas na sociedade atual. O conflito é uma presença constante na história da civilização e parte integrante do convívio social, e para enfrentá-lo é importante aceitar diferenças, aceitar posições distintas e dialogar sempre.

Nesse sentido, Ortega afirma que:

Um conflito não é necessariamente um fenômeno da violência, embora, em muitas ocasiões, quando não abordado de forma adequada, pode chegar a deteriorar o clima de convivência pacífica e gerar uma violência multiforme na qual é difícil reconhecer a origem e a natureza do problema (2002, p.143).

A mediação ${ }^{9}$ é tida como uma técnica extrajudicial de resolução de

\footnotetext{
9 "Os métodos complementares e adequados orientam-se pela ética da alteridade, reivindicando a recuperação do respeito mútuo e fortalecendo valores fundamentados na fraternidade e na solidariedade, a partir do restabelecimento da comunicação e do diálogo. Assim, a mediação e a conciliação cumprem o objetivo de atender às necessidades de cada parte, devolvendo a elas a capacidade de encontrar a resposta mais adequada ao seu conceito" (GIMENEZ; SPENGLER, 2016, p. 202).
} 
conflitos, por meio da qual as próprias partes, com o auxílio imparcial de um terceiro, buscam dialogar para resolver os seus conflitos de forma satisfatória. Por isso, seguindo Luis Alberto Warat, considera-se a mediação como "uma forma ecológica de negociação ou acordo transformador das diferenças", pois ocorrendo a mediação todas as partes resultam ganhadoras, uma vez que se chega a uma solução consensuada e não existe o ressentimento de sentir-se "perdedor" (1998, p.5).

Conforme ressalta Lília Sales (2004), a "mediação representa assim um mecanismo de solução de conflitos pelas próprias partes que, movidas pelo diálogo, encontram, uma alternativa ponderada, eficaz e satisfatória, sendo o mediador a pessoa que auxilia na construção desse diálogo".

As noções de culpa e castigo são intensamente enraizadas em nós. Por isso mesmo, perdoar é um ato que exige, em primeiro lugar, lutar contra si mesmo, em algum nível, para que se consiga eximir a culpa que é atribuída ao Outro e, com isso, superar internamente a vontade de castigá-la. Nesse sentido:

Perdoar é o ato de libertar o outro da culpa, mas é mais que isso. Em sua função libertária, o perdão liberta quem o pratica. É um ato de grandeza de espírito, que representa, acima de tudo, uma doação. For-give, vor-geben, per-dón. Praticamente em todos os idiomas a palavra perdoar obedece a sua origem do latim vulgar perdonare, formada pela junção do prefixo per (através de) com a palavra donare, que representa o ato de doar ou, melhor ainda, dar-se. Perdoando, a pessoa doa o que há de melhor em si mesma - a compreensão, a compaixão e a esperança (MUSSAK, 2010).

Portanto, pode-se afirmar que a liberação do perdão marca um reinício nas relações que eram conflituosas, pois permite aos sujeitos desfrutar da sensação de alívio e possibilita a tranquilidade de conviver consigo mesmo, talvez por isso, seja tão difícil de ser praticado. Ademais, há tempos que o conceito de perdão abandonou o aspecto apenas religioso, para permear as relações sociais, uma vez que sem ele a vida em comunidade não seria possível, já que cada ofensa suscitaria uma inimizade.

Nesse sentido, o perdão é uma resposta libertária:

Se não fôssemos perdoados, eximidos das consequências daquilo que fizemos, a nossa capacidade de agir ficaria por assim dizer limitada a um único ato do qual jamais nos recuperaríamos; seríamos para sempre as vítimas das suas consequên- 
cias, à semelhança do aprendiz de feiticeiro que não dispunha da fórmula mágica para desfazer o feitiço. Se não nos obrigássemos a cumprir as nossas promessas não seríamos capazes de conservar a nossa identidade; estaríamos condenados a errar desamparados e desnorteados nas trevas do coração de cada homem, enredados nas suas contradições e equívocos - trevas que só a luz derramada na esfera pública pela presença de outros que confirmam a identidade entre o que promete e o que cumpre poderia dissipar. Ambas as faculdades, portanto, dependem da pluralidade; na solidão e no isolamento, o perdão e a promessa não chegam a ter realidade: são no máximo um papel que a pessoa encena para si mesma (ARENDT, 2016).

Ainda segundo Arendt, o perdão é uma experiência que não se pode ter sem os outros, sem a presença da pluralidade, nunca um ato de si consigo mesmo.

[o perdão] é a única forma de reação que não 're-age' apenas, mas age de novo e inesperadamente, sem ser condicionada pelo ato que provocou e de cujas consequências liberta tanto quem perdoa quanto o que é perdoado [...] é a liberação dos grilhões da vingança (MUSSAK, 2015).

O perdão é oposto à vingança, e é necessário amor, uma vez que o respeito e consideração são suficientes para desculpar o mal feito. Na mediação, enquanto processo transformativo, o perdão simboliza a reconciliação, a liberação de sentimentos negativos, o transformar-se internamente. Assim:

[...] Os conflitos nunca desaparecem, se transformam; isso porque, geralmente, tentamos intervir sobre o conflito e não sobre o sentimento das pessoas, Por isso, é recomendável, na presença de um conflito pessoal, intervir sobre si mesmo, transformar-se internamente, então, o conflito se dissolverá.

$\mathrm{O}$ mediador deve entender a diferença entre intervir no conflito e nos sentimentos das partes. $\mathrm{O}$ mediador deve ajudar as partes, fazer com que olhem a si mesmas e não ao conflito, como se ele fosse alguma coisa absolutamente exterior a elas. [...] (WARAT, 2004, p.26).

Ou seja, a partir da mediação é possível ocorrer o distanciamento do passado, dos ressentimentos, possibilitando a liberação do perdão, permitindo que os envolvidos convivam em harmonia com o presente. Sentimentos de punição e culpa são convertidos por um olhar para si e para o outro, e em busca do bem comum, em libertação.

Nesse sentido, importante mencionar que o maior atributo que se espera 
das perguntas feitas no procedimento da mediação é que possa promover a reflexão, convide à expressão e à decisão sobre algo, após pensar a respeito com cuidado e critérios éticos que considerem o outro (ALMEIDA, 2014, p. 257). Assim, a liberação do perdão também se constitui como resposta, ao se restabelecer a relação social entre os mediandos. Demonstra a calma das emoções, o livramento do sentimento de ódio e injustiça.

Conforme ressalta Muller:

A mediação quer, assim, criar na sociedade um lugar onde os adversários possam aprender ou reaprender a comunicar, a fim de chegarem a um pacto que lhes permita viver juntos, senão numa paz verdadeira, pelo menos numa coexistência pacífica (2006, p. 170)

Destaca-se que, quando a pessoa tem seu relato acolhido, e é chamada a refletir sobre seu modo de agir, pensar e se comunicar, acaba por contemplar sua posição inicial de forma mais profunda. É quando o indivíduo envolvido no conflito começa a identificar seus sentimentos em relação àquela questão e também a sua responsabilidade sobre o ocorrido, ponderando sua necessidade real e expectativa. Passa-se, então, a desenvolver um olhar sensível sobre o outro, comunicando-se com este outro de maneira não agressiva.

Vislumbra-se, nessa ótica, que o instituto da mediação ajuda a desenvolver relações de empatia, formar seres humanos mais seguros, uma vez que conseguem realizar o exercício de se colocar no lugar do outro, entender melhor seus próprios sentimentos, perdoar o outro e acima de tudo a si mesmo, e ter clareza sobre suas emoções e comportamentos.

\section{CONSIDERAÇÕES FINAIS}

Observa-se, a partir do estudo realizado, que o exercício da escuta ativa pode ser visto como uma ferramenta essencial, pois ajuda a se relacionar com os demais, resolver conflitos, compreender sentimentos e opiniões de terceiros, pois, o diálogo é o que ampara a existência social do humano e, por isso, deve ter suas bases no respeito e na cooperação. Nesse sentido, a escuta ativa na mediação estimula os envolvidos em um conflito a expressar suas emoções e instiga as partes a ouvirem uma à outra, não dando margem para reforçar relações de medo e agressividade. 
Assim, o terceiro facilitador deve ajudar a parte ouvinte a perceber o conteúdo e a emoção da mensagem proferida; auxiliar as partes a se expressarem e a explicarem o seu ponto de vista sobre o conflito e os seus sentimentos envolvidos, mostrando aos envolvidos que a expressão dos sentimentos é necessária à compreensão da profundidade da controvérsia. Ainda, contribui para criar um ambiente capaz de garantir liberdade e segurança para que a divergência seja abertamente discutida pelas partes.

Destaca-se, nesse sentido, que mediação procura compreender o mal praticado e desenvolver empatia para com a vítima e o ofensor; escutar e atender as necessidades da pessoa que sofreu o dano e daquela que o provocou; estimular o compromisso de assumir as consequências dos próprios atos e a responsabilidade por meio da reflexão pessoal dentro de um processo de planejamento colaborativo; reintegrar as partes como membros valiosos que contribuem para a sociedade, criando ambientes de solidariedade. $\mathrm{Ou}$ seja, é uma forma de transformação das relações conflituosas, pautada na comunicação clara e sensível. Por isso, a escuta ativa atenta às narrativas construídas por cada um, e a formulação de perguntas que provoquem os impactos almejados pela mediação, sendo peça-chave na intervenção dos mediadores e no decorrer do processo.

Cada ser tem suas particularidades, características próprias que definem seu modo de encarar suas angústias. Nesse sentido, é preciso a acolhida do outro que possibilita a abertura à alteridade. A alteridade exige desprendimento no sentido de acolher e responder ao outro, de questionar as relações, valores e vontades. O exercício de alteridade deve ser constante, e se dá pela exterioridade.

Por fim, ao estimular a comunicação entre as partes em conflito, analisando este não apenas a partir da sua perspectiva, separando interesses e sentimentos, e desenvolvendo o controle de interações destrutivas, a mediação possibilita a transformação e a pacificação nas relações sociais, reconhecendo a importância da sensibilidade e do perdão para o desenvolvimento da sociedade. 


\section{REFERÊNCIAS}

ALMEIDA, Tania. Caixa de Ferramentas em mediação: aportes práticos e teóricos. São Paulo: Dash, 2014.

ARENDT, Hannah. A condição humana. Forense Universitária; Edição: 13a , Nova Edição,2016, p.295-300.

BACCELAR, Roberto Portugal. A mediação no contexto dos modelos consensuais de resolução dos conflitos. São Paulo: Revista do Processo, n. 95, p. 122-134, jul./ se.1999, v. 24.

BOLZAN DE MORAIS, José Luis; SPENGLER, Fabiana Marion. Mediação e arbitragem: alternativas à jurisdição. 2 ed. Porto Alegre: Livraria do Advogado, 2008.

BOLZAN DE MORAIS, José Luis; SPENGLER, Fabiana Marion. Mediação e arbitragem: alternativas à jurisdição. 2 ed. Porto Alegre: Livraria do Advogado, 2008.

BREITMAN. S.; PORTO, A. C. Mediação familiar: uma intervenção em busca da paz. Porto Alegre: Criação Humana, 2001.

BUSH, Baruch. Robert A.: FOLGER, Joseph P. The Promisse of mediation: the transformative approach to conflict. San Francisco: Jossay Bass, 2004.

CEZAR-FERREIRA, Verônica A. da Motta. Família, Separação e Mediação uma Visão Psicojurídica. 3a ed. São Paulo: Método, 2011.

DEMARCHI, Juliana. Técnicas de conciliação e mediação. In: Mediação e gerenciamento do processo. São Paulo: Atlas, 2007.

FACHADA, Maria Odete. Psicologia Relações Interpessoais. Lisboa, Ed. Rumo, 1991.

FISCHER, Robert; URY, William; PATTON, Bruce. Como chegar ao sim. Rio de Janeiro: Imago, 1994.

FOLBERG, Jay. Divorce Mediation. New York: The Guildford Press, 1988. 
GIMENEZ, Charlise Paula Colet; SPENGLER, Fabiana Marion. O mediador na resolução 125/2010 do CNJ: um estudo a partir do Tribunal Múltiplas Portas. Águas de São Pedro: Livronovo, 2016.

MENDONÇA, A. H. B. A Reinvenção da tradição do uso da mediação. Revista de

MENDONÇA. Rafael, (Trans) Modernidade e Mediação de Conflitos, Joinville . Editora Latra dágua, 2008.

MOORE, Christopher W. O processo de mediação: estratégias práticas para a resolução de conflitos. 2. ed. Porto Alegre: Artmed, 1998.

MORAIS, Jose Luis Bolzan. Mediação e arbitragem: alternativas à jurisdição! Porto Alegre: Livraria do Advogado, 1999.

MUSSAK, Eugênio. Preciso dizer o que sinto. Editora: Integrare; Edição: 1ª 2015.

NORTHFLEET, Ellen G. “Novas fórmulas para resolução de conflitos”. In: TEIXEIRA. Sálvio de Figueiredo. O judiciário e a constituição. Brasília: Saraiva, 1994. p. 235.

SALES, Lilia Maia de Morais. Justiça e mediação de conflitos. Belo Horizonte: Del Rey, 2004.

A cidadania em debate: a mediação de conflitos. Fortaleza: Universidade de Fortaleza, 2005.

Mediare: um guia prático para mediadores. 3 ed., rev., atual. e ampl. Rio de Janeiro: GZ ed., 2010.

SIMMEL, Georg. Sociologia. Tradução de Carlos Alberto Pavanelli et. al. São Paulo: Ática, 1983.

SIX, Jean François. Dinâmica da mediação. Tradução de Giselle Groeninga de Almeida, Águida Arruda Barbosa e Eliana Riberti Nazareth. Belo Horizonte: Del Rey, 2001.

SPENGLER, Fabiana Marion. Retalhos da Mediação. Santa Cruz do Sul: Essere nel Mondo, 2014. 
VASCONCELOS, Carlos Eduardo de. Mediação de conflitos e práticas restaurativas. Modelos, processos, ética e aplicações. São Paulo: Editora Método, 2008.

VEZZULlA, Juan Carlos. Teoria e Prática da Mediação. Paraná: Instituto de Mediação e Arbitragem do Brasil, 1998.

A mediação para uma análise da abordagem dos conflitos à luz dos direitos humanos, o acesso à justiça e o respeito à dignidade humana. In: Mediação de Conflitos. Luciana Aboim Machado Gonçalves da Silva, organizadora. São Paulo: Atlas, 2013.

WARAT, Luis Alberto. A Ciência Jurídica e seus dois maridos. Santa Cruz do Sul : Faculdades Integradas de Santa Cruz do Sul, 1985.

(Coord.), Ecología, psicoanálisis e mediação. Em nome do acordo. A mediação no Direito. Trad. J. Rodrigues. Buenos Aires: Almed, 1998.p.5-59.

O ofício do mediador. Florianópolis: Habitus, 2001. V I.

. Surfando na pororoca: o ofício do mediador. Florianópolis: Fundação Boiteux, 2004.

A rua grita Dionísio! Direitos humanos da alteridade, surrealismo e cartografia. Tradução e organização Vívian Alves de Assis, Júlio Cesar Marcellino Júnior; Alexandre Morais da Rosa. Rio de Janeiro: Editora Lumen Juris, 2010.

Direito, sujeito e subjetividade: para uma cartografia das ilusões. Captura Críptica: direito política, atualidade. Revista Discente do Curso de PósGraduação em Direito. - n.2., v.2. (jan/jun. 2010) - Florianópolis, Universidade Federal de Santa Catarina, 2010. 